\title{
The integration of verbal and non-verbal materials in some instances of written scientific discourse
}

\section{Claude Sionis}

\section{OpenEdition}

\section{Journals}

Electronic version

URL: http://journals.openedition.org/asp/3191

DOI: 10.4000/asp.3191

ISSN: 2108-6354

\section{Publisher}

Groupe d'étude et de recherche en anglais de spécialité

\section{Printed version}

Date of publication: 1 December 1997

Number of pages: 339-355

ISSN: 1246-8185

\section{Electronic reference}

Claude Sionis, "The integration of verbal and non-verbal materials in some instances of written scientific discourse », ASp [Online], 15-18 | 1997, Online since 18 November 2012, connection on 04 May 2019. URL : http://journals.openedition.org/asp/3191 ; DOI : 10.4000/asp.3191

This text was automatically generated on 4 May 2019.

Tous droits réservés 


\title{
The integration of verbal and non- verbal materials in some instances of written scientific discourse
}

\author{
Claude Sionis
}

\section{Introduction}

1 The origin of the present study is the organisation in the École Centrale de Nantes of a widely attended international conference in the field of integrated design and manufacturing in mechanical engineering. ${ }^{.}$The more than 200 speakers had to submit the entire and final texts of their papers prior to presenting them orally. The corpus consists of the first 30 written papers submitted in English by NS and NNS researchers to the scientific committee. What is studied in this paper is the material representation of a coherent intellectual activity as a physical assembly of verbal materials (VM) and non- (or rather partially-) verbal materials (NVM) within a cohesive type of discourse.

2 What soon became very obvious, and partly prompted the present study, was the realisation that, in the domain concerned which involved computer science, mechanics, system engineering and materials behaviour, the researchers used NVM as their focal points and indeed the very backbone of their papers. Their verbal discourse was created and organised to develop and comment on NVM and not the other way around. NVM were definitely not used to "illustrate" a predominantly verbal type of communication; they were the very subject and the main mode of communication.

When questioned about the way they had organised their writtenpapers, 15 out of 23 of our researchers, NS and NNS alike, said that NVM were the main elements around which they had organised their comments. Although NVM traditionally call for mute exhibition, the reverse was true in this case in that the most straightforward NVM sometimes generated the longest verbal comments. This was verified in the six (out of 30) articles which included very simple NVM, e.g., the cross-section picture of a hexagonal nut. 
The object of the study was not the way the oral presentations were delivered, but it was very obvious to the attending non-specialist EST teachers that those presentations were also a constant alternation between all the possible combinations of VM/NVM: complex VM/ complex NVM, complex VM/simple NVM, simple VM/simple NVM, simple VM/ complex NVM. Although not always spoken in words, there was no doubt, despite the variety, about the singleness and integration of the discourse used.

\section{Hybrid concepts and hybrid representations}

Because of their educational background, which is generally in the humanities, teachers of language for specific purposes or researchers in applied linguistics are often at a loss when confronted with textual items belonging to logical systems which differ radically from natural language. Although mathematical formulae and equations can all be verbalised, they are probably among the most extreme cases in this respect. Those teachers and linguists are also often puzzled by non-verbal materials in general like drawings, schematics, graphs, tables, diagrams and other "illustrations". One possible solution is to look the other way and say that this is no longer one's domain. Trimble (1985: 158) writes:

It is not the purpose of the English teacher to train the non-native (or native) reader in understanding the more difficult visuals [...] that task should be left to the teachers of the technical courses where such visuals are studied and sometimes produced.

6 What Trimble also defends is the opinion along which NVM are mostly "illustrations" of VM and, paradoxically enough, both providers of additional information and "textsavers". Having said that the statements made by the text should be such that they tell the reader when and where to find the visual in the text and what to look for in the visual, Trimble acknowledges the indisputable primacy, for him, of VM:

The function of visual aids is to add information to that given by the discourse; as a result, we find visual aids only in conjunction with other rhetorical features. All visual aids have one characteristic in common: providing information, usually detail, that is tedious to read in solid text, or is difficult or impossible to describe accurately in words alone (....) without some kind of text explanation, no type of visual provides information with the same clarity and precision that well-written scientific and technical discourse does. (Trimble 1985: 102)

7 It is obvious from what Trimble writes that if NVM are found in the midst of scientific discourse, their second-class status as conveyors of reliable scientific information is clearly established. A rather different view is expressed by Widdowson (1978: 73):

In a very wide range of written discourse we will find such non-verbal devices as drawings, flow-charts, tables, graphs, charts and so on which are incorporated into the discourse and relate to the actual verbal text to form a cohesive and coherent unit of communication. The interpreting of written discourse involves the processing of these non-verbal elements and a recognition of their relationship to the verbal text. (NVM) represent the basic elements, or the "deep structure" of scientific discourse in which different linguistic textualizations are the surface variants.

Widdowson recognises the integration of VM and NVM within scientific discourse but does so in the tradition of Sapir (1967) who held that the symbolic component of scientific language was universal and less likely to be misinterpreted than all further translations in different national languages. However, as Régent points out, rightly in my view, 
scientific language only exists as far as terminology is concerned, no object is scientific by essence, only the researcher's discourse makes it scientific (Régent 1994: 56, my translation).

9 The truth may lie in between and there may be no more grounds for saying that the hardcore of scientific discourse lies mostly in VM (Trimble) than there are for saying that NVM are its "basic elements" (Widdowson).

One of the characteristics of scientific discourse is not to speak in words only. At least in the corpus studied, each individual researcher's style and discourse appeared to be personal and located, as it were, on a scale going from a purely symbolic mode of representation, resting exclusively on NVM, to an exclusively verbal mode with all the possible in-between combinations and proportioning of VM and NVM. The result was, in all cases, a hybrid type of written discourse which may prompt the question of knowing whether scientific and technological facts are conceived mentally in a hybrid way too.

Trimble (1985: 104) does ask the question of which came first, the verbal or the nonverbal, but he does not really answer either the "surface" level question of knowing where to put a visual in a text or text in a visual, nor the deeper level question of knowing why some concepts spontaneously occur to scientists, and are, in their view, best represented as NVM, VM, or compounds of VM and NVM.

12 Applied linguists and teachers of Languages for Specific Purposes (LSP) are familiar with another kind of hybridity: how much must be known of a student's specific subject when teaching the language associated with this subject. This has been a crucial and much debated issue ever since the rise of the notion of LSP (Hutchinson \& Waters 1987; Spack 1988; Johns \& Dudley-Evans 1991; Dudley-Evans 1993; and many others). But the issue of processing and teaching hybrid but coherent and cohesive discourse goes beyond the usual opposition between common-core and subject specific approaches. It certainly also reaches beyond the comparatively safe area of linguistics and of verbal language, the semiotic system most LSP teachers and applied linguists are familiar with.

Some ESP/EAP practitioners will probably feel that the answer to the question of how best to teach the hybrid domain of science and language lies in team-teaching between language and subject specialists, but the study and teaching of what makes NVM and VM an integrated discourse is mostly the responsibility of the linguist. One reason among many is that, at least as far as written text is concerned, nearly all NVM can be verbalised if necessary. Nuttall (1982: 53) very appropriately points out that NVM should in actual fact be defined as "non-linear text". They could also be called partially verbal materials (PVM).

\section{A hybrid cohesive system}

\section{Lexico-syntactic cohesion}

Linguists confronted with the task of demonstrating the cohesiveness of scientific discourse will probably agree on a minimum definition of discourse as being

a collection of connected language units such as sentences and paragraphs that together make up a coherent cohesive text (Trimble 1985: 2)

Studies of inter-sentential cohesion are numerous, starting from Halliday \& Hasan 1976, Quirk, Greenbaum, Leech \& Svartvik 1985, to Tyler \& Bro 1992, 1993 (NS and NNS general 
discourse), Osborne 1994 (NNS scientific discourse). The object of these studies is what Nuttall calls "linear text" and the observations made about the use of cohesion markers in scientific discourse as compared with general "language-in-use" mostly differ in distribution and rate of occurrence. No marked difference is observed in the nature of the connectors used, which have been classified in categories by Halliday and Hasan (1976): additive, e.g., and; adversative, e.g., however; causal, e.g., consequently; temporal, e.g., then, or in further more finely-tuned sub-categories of connectors by Quirk et al. like: reinforcing, appositive, reformulating, equative, concessive, antithetic, resultive, enumerative, and summative.

In the case of non-linear modes of communication, like commercials which combine words and pictures, cohesion and coherence are achieved not grammatically, in the conventional sense of the term, but semantically, according to what I would call a principle of "thematic consistency". This principle rests essentially on the physical ability of the observer's eye to capture for instance the whole of a composite VM/NVM page in a magazine, and process it semantically as a single integrated message. In this case, the "theme" of the commercial message is attributable in a diffuse way to the combined action of the VM and NVM components perceived as one integrated construct.

If we consider written scientific communication as exemplified by the submitted research papers, we may assume that some representation procedures fit more closely than others the way initial concepts appeared in the mind of the hard science researcher. In 6 of the submitted papers, the scientific committee identified a few inadequacies like elliptic verbal passages or inexplicably incomplete diagrams. When questioned about what was perceived by others as mere omissions, two co-authors responded that the points concerned were for them simple and self-evident truths which only needed to be stated to be accepted. The best evidence, they said, was the fact that they had felt no need to discuss those points among themselves.

At this stage of early intellectual creation, it can be surmised that concepts are represented as single integrated constructs too. Once this intellectual activity has been applied to various real-life procedures, experiments, tests and practical realisations, the need arises to reconstruct the whole intellectual and practical process and associate linear and non-linear modes of representation. In the case of the research paper, this association occurs in writing by means of a distribution of syntactic and other linguistic cohesion markers. The number and nature of these markers often depend on the amount of verbal encoding carried by each non-linear mode used.

19 Figure 1 lists the types of partially verbal materials (PVM) recorded in a production corpus of 30 papers in the field of integrated design and manufacturing in mechanical engineering. The papers average 3,600 words each and, in a rather rough type of comparison, exhibit a solid text to PVM ratio of 1:1.6 obtained when considering the amount of page space occupied by each type of communicative mode.

20 The different PVM listed in Fig.1 are entered in decreasing order of verbality, from "not spontaneously verbalised by non-specialists", e.g., mathematical equations and formulae, to "exclusively non-verbal materials", e.g., captionless or unlabelled photos or drawings.

21 Equations and formulae were classified as PVM whenever they appeared as distinct blocks comparable to paragraphs and not included in "verbal" paragraphs. As such, equations/formulae accounted for 58 of the 151 examples of PVM, being by far the preferred type of PVM. Considering mathematical language as PVM should be viewed, at 
this stage, only as a convenient way of discriminating between what is likely to be more accessible to readers trained in the humanities, i.e., verbal text and visual materials, and what is not.

The borderline between predominantly verbal PVM and predominantly visual PVM is certainly not easy to draw. At this stage of the study, a very loose definition of the former category would be "materials in which the information conveyed depends mostly on its verbal component". Flow-charts, for example, can still be interpreted with a relatively small risk of error when their string-like pictorial arrangement is withheld, provided the text blocks are not merged into one single paragraph. Likewise, the predominantly visual PVM depend mostly on their pictorial component to convey the gist of their message.

Figure 1. Partially verbal materials in decreasing order of verbality

\begin{tabular}{|c|c|c|}
\hline Predominantly verbal PVM (71.5\%) & $\begin{array}{l}\text { Number of } \\
\text { occurrences }\end{array}$ & Percentage \\
\hline Mathematical equations \& formulae & 58 & $38.41 \%$ \\
\hline Complex flow-charts \& tree-diagrams & 18 & $11.92 \%$ \\
\hline Simple flow-charts \& tree-diagrams & 16 & $10.59 \%$ \\
\hline Hybrid words/numbers tables & 9 & $5.96 \%$ \\
\hline Numbers-only tables & 4 & $2.64 \%$ \\
\hline Words-only tables, pie-charts and similar & 3 & $1.98 \%$ \\
\hline Total & 108 & $71.5 \%$ \\
\hline Predominantly visual PVM (28.5\%) & & \\
\hline $\begin{array}{l}\text { Photos, exploded views, drawings with labels, arrows and } \\
\text { captions }\end{array}$ & 20 & $13.24 \%$ \\
\hline $\begin{array}{l}\text { Mute photos, graphs and drawings (Fig. number }+ \text { caption } \\
\text { provided) }\end{array}$ & 15 & $9.93 \%$ \\
\hline $\begin{array}{l}\text { Other PVM: mute maps, sketches, hybrid PVM, (e.g. photo } \\
\text { +tree diagram), computer-generated meshings of shapes, etc. }\end{array}$ & 8 & $5.33 \%$ \\
\hline Total & 43 & $28.5 \%$ \\
\hline GRAND TOTAL & 151 & $100 \%$ \\
\hline
\end{tabular}

Lexico-syntactic cohesion really exists between general language text and the mathematical language of equations and formulae, even though traditional markers (and, but, however, so, etc.) do not appear as such within equations. Well-known mathematical symbols like $\approx$ (is approximately equal to), => (entails), $\leq$ (less than or equal to), $\geq$ (greater than or equal to), $\infty$ (is proportional to), etc. are found everywhere within equations 
either to act as deictic and/or predicative elements, or to introduce cohesive relations. These relations between sub-parts of equations are very close to those introduced by more traditional grammatical markers identified by Halliday and Hasan like in addition (additive), equally (additive/equative), alternatively (opposition/antithetic), consequently, therefore, then, as a result, hence, thus (causal/resultive), etc.

What matters for the present purposes is that lexico-syntactic cohesion markers are found in the VM/NVM border area in proportions which are comparable to those occurring between VM passages (e.g. paragraphs) when "non-exclusively verbal materials" are concerned. In other words, the writers consciously or unconsciously recognise these materials as text to be integrated with other text in a conventional textual way.

The dividing line between "mostly text" and "mostly visual", and "non-text", is not easy to draw. This is probably because of the principle of thematic consistency already alluded to, which results in the reader capturing the whole of the semantic content of VM-NVM constructs.

Constructs of that sort can be complex macro-organisations and extend over several pages of written demonstration. In this case, the reader's attention constantly alternates between VM and NVM in an attempt to establish semantic cross-reference between mutually supporting components.

The constructs can also be simple one-to-one VM-NVM micro-organisations perceived as single integrated sign structures. This is where the hybridity of written scientific communication probably lies: at the very heart of those micro and macro semiotic constructs or sign-systems.

The spectrum of lexico-syntactic marker usage ranges from nearly equal rates of lexicosyntactic markers of cohesion (such as, this, by, becomes, leads to, is determined by, is equal to, etc.) between general and mathematical language, to no real VM-NVM transition other than the recurrent and ubiquitous "the (name of phenomenon given) shown in Fig. (number given)...".

29 Also worth noting is the equally ubiquitous colon sign (:) which, although not meaning the same in general and mathematical language, is nevertheless a hybrid non-verbalised cohesion marker used by researchers following nearly all deictic phrases like such as, is determined by, is written, etc.

However, when cohesion is not effected at the VM/NVM border area (e.g. between the end of a paragraph and a diagram) the lexico-syntactic articulation can be said to be "intratextual", i.e., cohesion is achieved between verbal elements only. We have, in fact, lexical reference in which the same words, more often nouns, are repeated in the VM and in the verbal part of the partially-verbal materials. In this case however, intratextual reference in the VM can be said to be almost inversely proportional to the amount of verbality contained in the NVM.

31 An example of this is when a mostly visual diagram is preceded or followed by extensive discussion or comments. In this case, all dimensions are expressed in figures and units as in figure 2. 


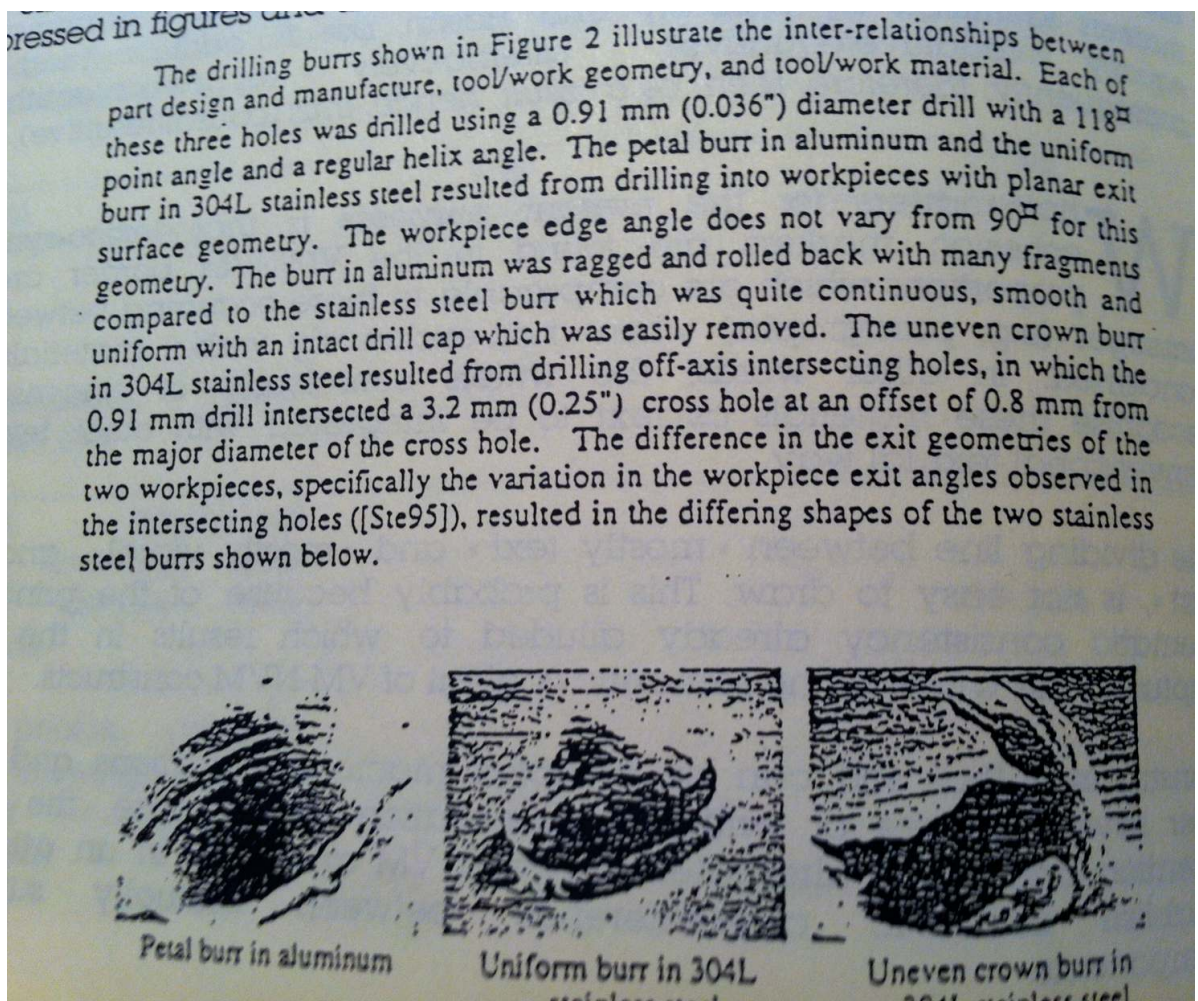

Stein \& Dornfeld 1996: 195 
was trying to do" also contributes to the notion of semantic cohesion as being a superordinate level of organisation above that of syntactic cohesion.

\section{Semantic cohesion}

For the lexicometric school (Demonet 1974; Lafon 1984), meaning exists through networks which extend beyond the traditional linear arrangement of verbal text. The real guiding points in these networks are the graphic words and signs, called "formal items", which are identified with no reference to lexical or grammatical categories, e.g. whether verbs are used in a specific tense or mode.

These networks have a paradigmatic type of organisation between equivalent terms or signs which exist on a semantic basis only. They can thus be composed of items belonging to different semiotic or codic systems. In the case of our scientific papers, a concept is often developed by resorting to several systems in alternation, depending on their appropriacy in conveying the desired meaning. We have the examples of information first presented via a graph which is subsequently developed in verbal form, and then again exemplified by a more detailed graph illustrating a point of detail mentioned verbally.

The semantic networks identified by the lexicometrists also have a syntagmatic type of organisation, inasmuch as the physical position assumed by a formal item within a VM or an NVM is a key element in the gradual way in which a concept is presented. This is an essential factor in semantic cohesion. It is because semantic networks are based both on the intertextuality between words and concepts, and between words within a specific type of discourse, register or genre, that the theory is applicable to written scientific communication. This can be understood by studying two aspects of specialised discourse which can also characterise hybrid VM/NVM scientific communication: "text sequences" and thematic progression (Maingueneau 1991: 214-221).

\section{Text sequences}

8 Several recent studies have underlined the special role played by NVM in written specialist texts and how scientists often referred to them before tackling the strictly verbal components (Lynch 1985; Amman \& Knorr-Cetina 1990). We might even be led to believe in the existence of implicit and unpublicised procedures followed by scientists in their processing of stereotyped categories of scientific communication acts.

Widdowson looks towards the methodology of science itself to account for the organisation of scientific discourse. Predictability of information would derive from a knowledge of:

the accepted format for the reporting experimental findings involving the combination of such constituent acts as statements of hypothesis, description of procedure, statements of findings, summary, and so on. (1979: 61)

A survey of the corpus did substantiate the notion of a given format of "constituent acts" being inevitably associated with the occurrence of a given NVM. When the verbal description of an industrial process grows too complex, a sentence identifying the difficulty like: "this probably needs to be illustrated by the following diagram" is produced. Likewise, when the description of intermediary steps or accessory equipment would divert the reader's attention from the main line of reasoning, another typical 
discursive arrangement of the text is to be found, like using an asterisk or short sentence between brackets to mention the existence of a diagram at the foot of the page.

The IMRD (Introduction-Methods-Results-Discussion) structure advocated, among others, by Swales (1990) for research articles, proved to be a surface structure not appropriate to account for the VM/NVM articulation. In terms of strict organisation, the semantic text sequence, which is in my opinion very close to Widdowson's notion of "constituent act", can be seen as a sub-structure of the IMRD pattern of research articles.

In a scientific text which can be either pure VM or a compound of VM and NVM, semantic sequences are linked by linear cohesion markers but also as a result of constraints bearing on the whole of the sequence. Sequences are both organised, e.g. mostly visual NVM associated with explanatory VM, and organising units (e.g. when relatively easy VM passages describing intermediary steps in a process call for diversified NVM like tables and flow-charts) as the description grows more complex. This is what Maingueneau (1991: 216) calls the "configurational dimension" of texts.

The description of the chronological development of scientific experiments often exhibits most of the characteristics of narrations; in this case, this configurational dimension is traditionally analysed as a series of sequenced propositions: Initial situation $\rightarrow$ complication $\rightarrow$ action $\rightarrow$ solution $\rightarrow$ final situation $\rightarrow$ conclusion. Popper (1972, quoted by Widdowson 1983) offers an adaptation of this cycle to scientific enquiry:

Problem $1 \rightarrow$ Trial solution $\rightarrow$ Error elimination $\rightarrow$ Problem 2

With very few exceptions, this pattern was found to be present and recurrent in the scientific papers studied, and a number of propositions in this micro-organisation can be said to be better served by VM, others by NVM. The two kinds of materials were often used in predictable ways, separately or in conjunction, e.g. sequenced processes were often best represented by flow-charts. There seems to be some sort of co-operation between the physical arrangement of VM/NVM items and specific functions in scientific communication like process-description, by far the most frequent function in the papers studied. There also seems to be some sort of unacknowledged, although effective, set of organisational rules for VM/NVM scientific discourse which are spontaneously used by scientists describing stereotyped aspects of their research.

In the corpus, most flow-charts, tables and tree-diagrams originated from the need to break down processes into chronological steps visually and this accounted for a majority of the NVM recorded (see Fig.1). Time-ordering seemed to be best represented by NVM which were often structured along the vertical axis (flow-charts). Space-ordering for its part was found in 6 out of 11 specifically dedicated diagrams to favour a rather circular arrangement with an outer-to-inner direction overall motion, as in the following diagram: 


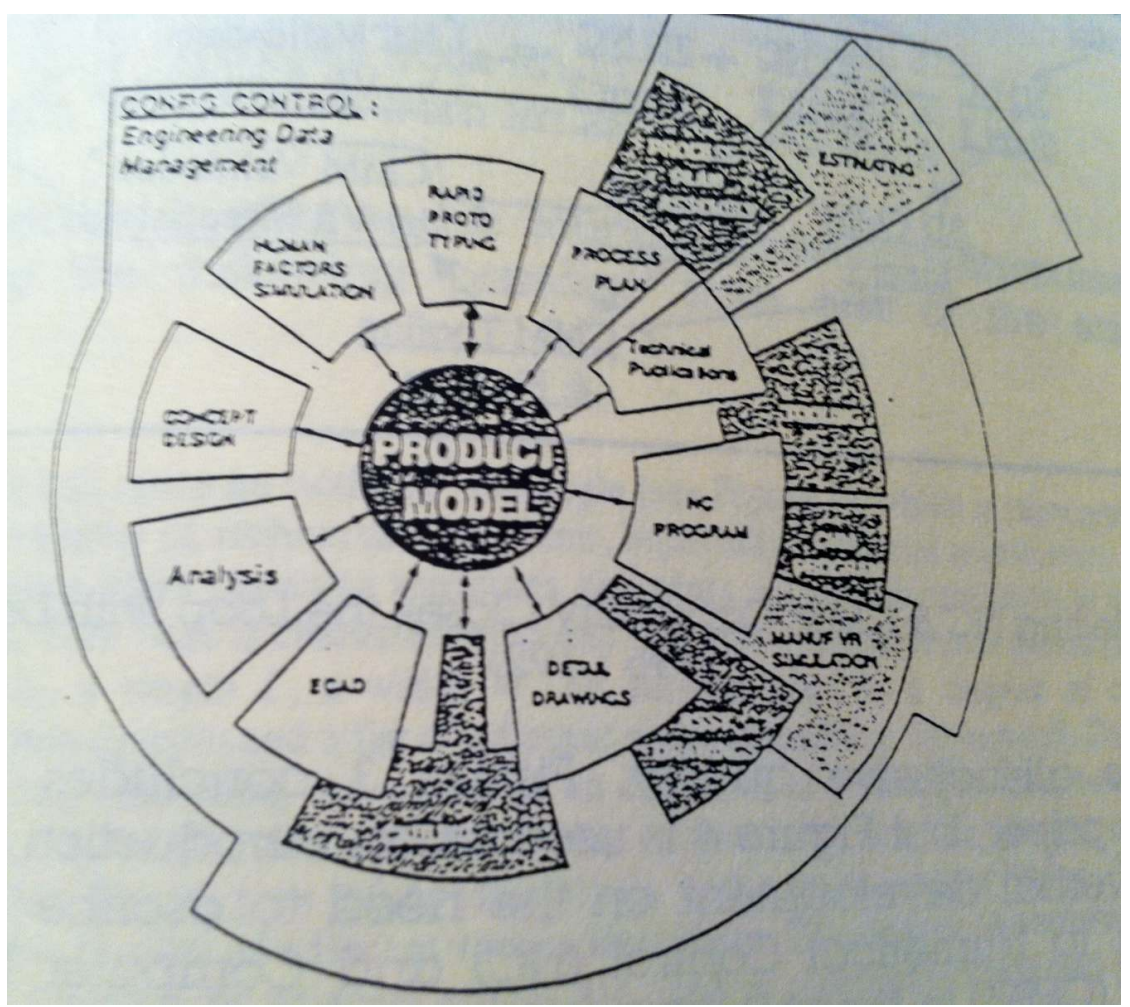

Bennett 1996: 188

lack of feedback between them (Process Plan Assembly, Tooling, CMM programming,
Assembly Drawings and Cabling);

51 3) the even more remote influence of factors like "Estimating" and "Manufacturing Simulation" which appear as marginal and whose links to the product model are so vaguely conveyed by the diagram that it is precisely this aspect of the global concept of "Concurrent Engineering" which is developed orally and in writing in the rest of the paper.

52 Hybrid time and space constraints, especially when variable and unpredictable elements outnumbered stable ones, were often represented as hybrid NVM with a double linear type of arrangement (e.g. vertical or horizontal arrows) and circular one (e.g. arrows "looping the loop") as in figure 4. 


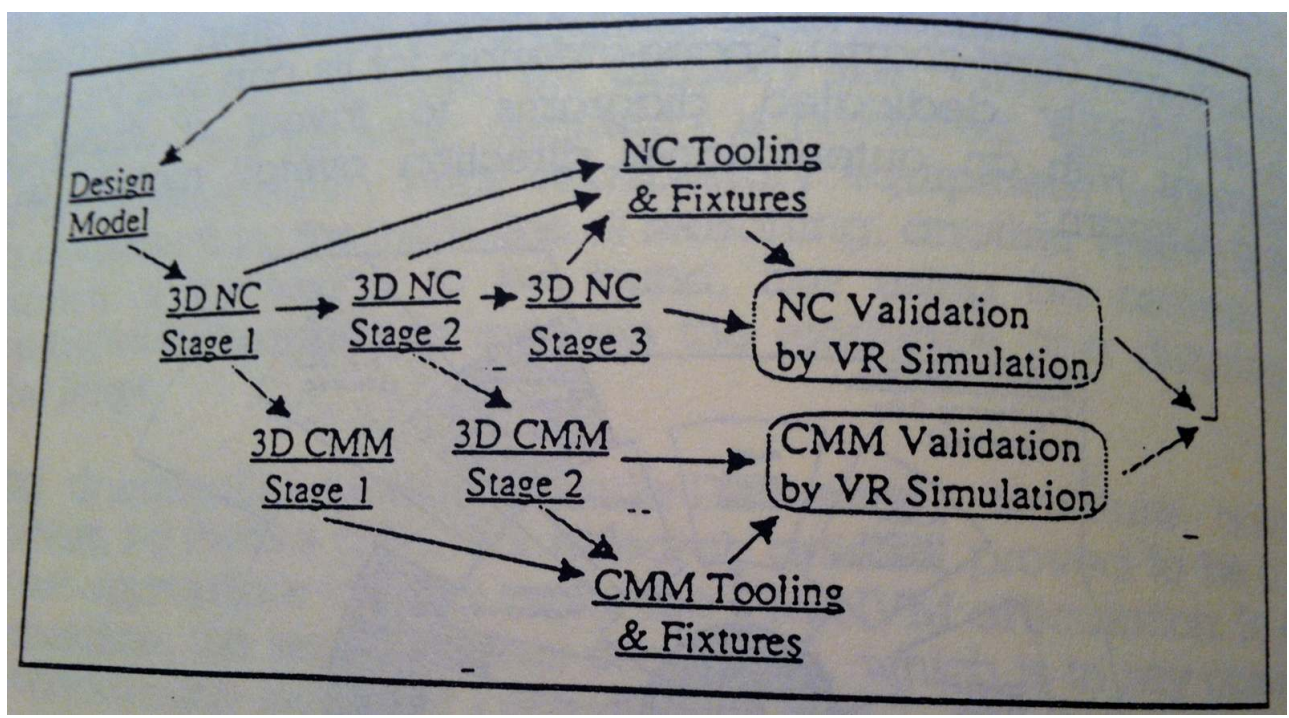

Bennet 1996: 192

Because of its all-inclusive quality, Figure 3 concludes an important passage in the paper, but Figure 4 is used as an introduction to a fairly long (400+ words) verbal development on the need to ascribe a definite and stable position to Numerical Control (NC) and Computer Modelling and Manufacturing (CMM) in the overall industrial production process. This is presumably due to the imprecise nature of this sort of diagram in which fundamentally different elements like processes and time-lengths are associated in a rather confusing manner.

\section{Thematic progression}

Like solid-text types of communication, VM/NVM integrated discourse is submitted to the two textual imperatives of progression and repetition. Thematic progression is not only a matter of jumping from one proposition to another, however smooth and logical the cohesion between these propositions. There always exists some sort of informational overlap and new information always includes some part of older information, even within the same sentence. This is one component of intratextual reference. There is also intertextual reference, an equally essential and traditional aspect of scientific communication: the borrowing from external sources as manifested by quotations.

The different constituents of a sentence carry either acquired or new information and a sentence can be said to be both a "syntactic-semantic structure and a structure carrying information within a certain textual dynamics" (Maingueneau 1991: 219, my translation).

Following the "School of Prague" terminology, the component carrying acquired information is called theme, whereas the rheme is the component which carries new information. Some theories or practices, often based on a logocentric and linguistic understanding of communication, imply that theme and rheme exist more or less objectively within each text or message. This is probably related to several other aspects of communication, such as the role of utterances, presuppositions and context as a 
dynamic element. If discriminating between theme and rheme is not always easy in sentences, it is even more complex when dealing with VM/NVM hybrid discourse. A type of thematic progression identified by Danes (1974)is called "linear progression", and is organised as in Table 1.

Table1

\begin{tabular}{|l|l|l|l|l|}
\hline Sentence 1: & Th. 1 & & $\rightarrow$ & Rh. 1 \\
\hline Sentence 2: & Th. 1' & (derived from Rh.1) & $\rightarrow$ & Rh. 2 \\
\hline Sentence 3: & Th. 1" & (derived from Rh.2) & $\rightarrow$ & Rh. 3 \\
\hline
\end{tabular}

This basic pattern is also to be found in scientific discourse and can be illustrated by the following passage from one of the scientific papers studied:

We call space an isothetic ${ }^{2}$ rectangle (see Figure 3), which is representative of a large majority of architecture problems, especially industrial architecture problems. The space class regroups attributes and class constraints common to all its subclasses. This class is characterised by an identifier, two reference points $(x l, y l$ ) and ( $x 2, y 2)$, a length $\mathrm{L}$, a width $\mathrm{W}$, an surface area S, a degree of constraints coefficient $d g$-cont and a list of adjacent space identifiers: list-esp-adj. The identifier is a string indicating the name of the instance of this class. The two reference points, the length, the width and the surface area are the integer constrained variables. The degree of constraints is a dynamic integer value. The list of identifiers is a set of adjacent space identifiers. The degrees of constraints and the list of identifiers of adjacent spaces are used in algorithms presented in section 3 and 4 .

Figure 5

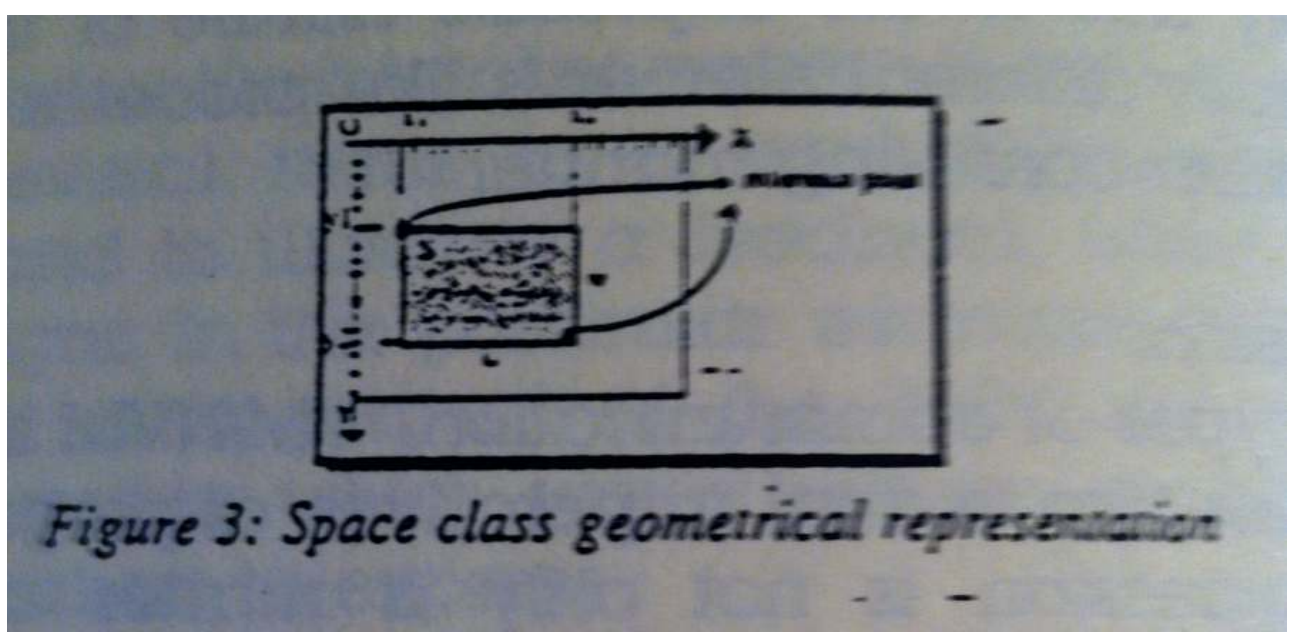

Medjoub \& Yannou 1996: 207

\begin{tabular}{|l|l|l|l|l|}
\hline “We call & space & an isothetic rectangle (see Fig. 3), & which & is representative of..." \\
\hline & Th. 1 & Rh. 1 & Th. 1' & Rh.2 \\
\hline
\end{tabular}


The intratextual deictic signalling of an illustration to refer to: "(see Fig. 3)" is not only a limited (and welcome!) explanation of Th.1 and Rh.1. We do not know at this stage what an isothetic rectangle is, but because the task of the figure mentioned is to illustrate globally a number of themes and rhemes developed in the rest of the paragraph, it is much too dense to be considered a mere complement of Rh.1.

In actual fact, the diagram in the figure can be described in words and is the pictorial equivalent of a cluster of themes and rhemes which can be verbalised and ordered in a number of possible ways. We can then assume that only VM can indicate how to interpret space-order displayed by NVM. Resorting to dense and cluttered NVM is unfortunately often due to space-saving recommendations from editors, and NVM are practically never limited to the specific illustrative role assigned to them by a caption or text passage. NVM seem to have a potential for different interpretations and they can thus hardly be considered as compatible steps in a theme/rheme type of discursive progression.

\section{Conclusion}

61 In the course of the present study I have tried to establish that VM/NVM integration within scientific discourse results from a number of factors and made the following observations.

All NVM explicitly or implicitly carry varying amounts of verbality. If lexico-syntactic cohesion is to be established, NVM must rather be recognised as partially-verbal materials.

As far as integration is concerned, the dividing line is not so much between VM and NVM but rather between, on the one hand, those components which are organised as rigid discursive units in which there is one-to-one correspondence between concepts and modes of representation, and, on the other hand, discursive units whose interpretative flexibility is a consequence of their incompletely-oriented, vague, and implicit character. In the corpus studied, NVM belonged more often than VM to the latter category.

VM and NVM have verbal overlap which makes it possible for them to be integrated by lexico-syntactic markers operating at their border areas, and by lexical reference when integration is not feasible at this peripheral transition area.

When lexico-syntactic cohesion is not possible, various pragmatic/ rhetorical devices are used which structure dissimilar components of discourse into integrated connected units. These pragmatic/rhetorical markers have no referential meaning, they act as "instructors" and participate in the procedural encoding of sentences.

66 The notion of "hybridity", as applied to written scientific communication, does not only concern the macro arrangement of a discourse which accommodates major VM and NVM passages by establishing cohesion between them. It also means a closer association of verbal and non-verbal elements within smaller hybrid micro-components (like partial verbal/non-verbal tables and graphs, or closely integrated text+ pictures/ figures/ formulae) to the extent that, at this stage, verbal and non-verbal contributors are no longer perceived as such, but as unified "thematic units".

Semantic cohesion passes through all linguistic and pragmatic categories and is manifested by semantic networks. These are composed of items belonging to different semiotic or codic systems and function in the paradigmatic and syntagmatic dimensions. 


\section{BIBLIOGRAPHY}

Amman, K., \& K. Knorr-Cetina. 1990. "The fixation of evidence”. In Lynch, M. and S. Woolgar (eds.), Representation in Scientific Practice. Cambridge, MA: MIT Press, 85-122.

Bazerman, C. 1985. "Physicists reading physics: Schema-laden purposes and purpose-laden schema". Written Communication 2, 3-24.

Bennet, G.R. 1996. "Manufacturing capability modelling for product design”. In IDMEE'96 Proceedings, vol. 1.

Danes, F. (ed.) 1974. Papers on Functional Sentence Perspective. The Hague: Mouton.

Dudley-Evans, T. 1993. "Subject-specificity in ESP: how much does the teacher need to know of the subject?". ASp 1, 1-9.

Halliday, M.A.K. \& R. Hasan. 1976. Cohesion in English. London: Longman.

Hutchinson, T. \& A. Waters. 1987. English for Specific Purposes: A learning-centred approach. Cambridge: Cambridge University Press.

Johns, A. \& T. Dudley-Evans. 1991. “English for Specific Purposes: International in Scope, Specific in Purpose". TESOL Quarterly 25/2, 297-314.

Lafon, P. 1984. Dépouillements et statistiques en lexicométrie. Genève: Slatkine-Champion.

Lynch, M. 1985. "Discipline and the material form of images: An analysis of scientific visibility". Social Studies of Science 15, 37-66.

Maingueneau, D. 1991. L'analyse du discours. Paris: Hachette Université.

Medjoub, B. \& B. Yannou. 1996. “A new tool for conceptual design in architecture”. In IDMEE'96 Proceedings, vol. 1.

Nuttall, C. 1982. Teaching Reading Skills in a Foreign Language. Oxford: Heinemann.

Osborne, J. 1994. "La cohésion dans les productions écrites d'étudiants en anglais de spécialité : un problème culturel ?". ASp 5-6, 205-216.

Popper, K. 1972. Objective Knowledge. Oxford: Oxford University Press.

Quirk, R. et alii. 1985. A Comprehensive Grammar of the English Language. London: Longman.

Régent, O. 1994. “L’article scientifique : un produit culturel”. ASp 5-6, 1994, 55-59. 
Sapir, E. 1967. Le Langage. Paris: Payot.

Spack, R. 1988. "Initiating ESL students into the academic discourse community: how far should we go?”. TESOL Quarterly 22/1, 29-52.

Stein, J. \& D. Dornfeld. 1996. "Integrated design and manufacturing for precision mechanical components”. In IDMEE'96 Proceedings, vol. 1.

Swales, J. 1990. Genre Analysis. Cambridge: Cambridge University Press.

Trimble, L. 1985. English for Science and Technology. A Discourse Approach. Cambridge: Cambridge University Press.

Tyler, A. \& J. Bro. 1992. "Discourse structure in non-native English discourse: the effect of ordering and interpretative cues on perceptions of comprehensibility". Studies in Second Language Acquisition 14/1, 71-86. (Quoted by Osborne, 1994).

Tyler, A. \& J. Bro. 1993. "Discourse processing effort and perceptions of comprehensibility in nonnative discourse: the effect of ordering and interpretative cues revisited". Studies in Second Language Acquisition 15/4, 505-522. (Quoted by Osborne, 1994)

Widdowson, H.G. 1978. Teaching Language as Communication. Oxford: Oxford University Press. Widdowson, H.G. 1979. Explorations in Applied Linguistics. Oxford: Oxford University Press.

Widdowson, H.G. 1983. Learning Purpose and Language Use. Oxford: Oxford University Press.

\section{NOTES}

1. Integrated Design and Manufacturing in Mechanical Engineering (IDMME '96), April 15-17, 1996. Ecole Centrale de Nantes, France. (Proceedings available from ECN Publishing Department, 1 rue de la Noe, 44072 Nantes Cedex 03, France)

\section{ABSTRACTS}

The article addresses the problem of the integration of dissimilar modes of representation (verbal, partially-verbal, and visual) found in some instances of written scientific discourse. It is based on the study of thirty scientific papers written in English by NS and NNS researchers in the field of mechanical engineering and computer-aided design and manufacturing. Various types of lexico-syntactic, semantic, and pragmatic/rhetorical devices which usually achieve cohesion in strictly verbal discourse are considered in the perspective of hybrid discourse integration. Reference is made to several representative approaches and to research into the communicative value of visual representation.

Cet article porte sur l'intégration de modes de représentation dissimilaires (verbal, partiellement verbal, et visuel) souvent présents au sein du discours écrit des sciences dites dures. Elle repose sur l'étude de trente communications scientifiques rédigées en anglais par des chercheurs natifs et non natifs dans les domaines du génie mécanique et de la conception/fabrication assistées par ordinateur. Plusieurs types de procédés lexico-syntaxiques, sémantiques et pragmatiques/ 
rhétoriques qui assurent habituellement la cohésion du discours strictement verbal sont envisagés dans la perspective d'un discours intégré hybride. La communication fait référence à diverses démarches représentatives au sein de la théorie de l'énonciation et à des recherches sur la valeur communicationnelle de la représentation visuelle.

INDEX

Mots-clés: cohérence, cohésion, discours scientifique écrit, intégration, pragmatique, rhétorique, sémiologie, verbal, visuel

Keywords: coherence, cohesion, integration, pragmatics, rhetoric, semiology, verbal, visual, written scientific discourse

\section{AUTHOR}

\section{CLAUDE SIONIS}

Claude Sionis est maître de conférences HDR en sciences du langage à l'Université de Nantes, IUT de Saint Nazaire. claude.sionis@wanadoo.fr 